\title{
Excess post-hypoxic oxygen consumption is independent from lactate accumulation in two cyprinid fishes
}

Genz, J.; Jyde, M.B.; Svendsen, Jon Christian; Steffensen, J.F.; Ramløv, H.

Published in:

Comparative Biochemistry and Physiology - Part A: Molecular \& Integrative Physiology

Link to article, DOI:

10.1016/j.cbpa.2013.02.002

Publication date:

2013

Link back to DTU Orbit

Citation (APA):

Genz, J., Jyde, M. B., Svendsen, J. C., Steffensen, J. F., \& Ramløv, H. (2013). Excess post-hypoxic oxygen consumption is independent from lactate accumulation in two cyprinid fishes. Comparative Biochemistry and Physiology - Part A: Molecular \& Integrative Physiology, 165(1), 54-60.

https://doi.org/10.1016/j.cbpa.2013.02.002

\section{General rights}

Copyright and moral rights for the publications made accessible in the public portal are retained by the authors and/or other copyright owners and it is a condition of accessing publications that users recognise and abide by the legal requirements associated with these rights.

- Users may download and print one copy of any publication from the public portal for the purpose of private study or research.

- You may not further distribute the material or use it for any profit-making activity or commercial gain

- You may freely distribute the URL identifying the publication in the public portal 
 \\ Excess post-hypoxic oxygen consumption is independent from lactate accumulation in two cyprinid fishes
}

\author{
Q13 J. Genz ${ }^{\text {a,* }}$, M.B. Jyde ${ }^{\text {b }}$, J.C. Svendsen ${ }^{\text {c,d,1 }}$, J.F. Steffensen ${ }^{\text {d }}$, H. Ramløv ${ }^{\text {b }}$ \\ a University of Manitoba, Department of Biological Sciences, 369 Duff Roblin, 190 Dysart Road, Winnipeg, Manitoba R3T 2N2, Canada \\ ${ }^{\mathrm{b}}$ Roskilde University, Department of Science, Systems and Models, Build. 18.1, P.O. Box 260, DK-4000 Roskilde, Denmark \\ ${ }^{c}$ Technical University of Denmark, National Institute of Aquatic Resources, Freshwater Fisheries, Vejlsøvej 39, DK-8600 Silkeborg, Denmark \\ d University of Copenhagen, Marine Biological Laboratory, Biological Institute, Strandpromenaden 5, DK-3000 Helsingør, Denmark
}

\section{A R T I C L E I N F O}

\section{Article history:}

Received 15 November 2012

Received in revised form 1 February 2013

Accepted 3 February 2013

Available online $\mathrm{xxxx}$

\section{Keywords:}

Common carp

Crucian carp

Anoxia

Anaerobic metabolism

\begin{abstract}
A B S T R A C T
Carassius carassius responds to hypoxic conditions by conversion of lactate into ethanol, which is excreted 23 over the gills. However, a closely related species, Cyprinus carpio, does not possess the ability to produce eth- 24 anol and would be expected to accumulate lactate during hypoxic exposure. While the increase in oxygen 25 consumption in fish required following strenuous exercise or low environmental oxygen availability has 26 been frequently considered, the primary contributing mechanism remains unknown. This study utilized 27 the close relationship but strongly divergent physiology between $C$. carpio and $C$. carassius to examine the 28 possible correlation between excess post-hypoxic oxygen consumption (EPHOC) and lactate accumulation. 29 No difference in the EPHOC: $\mathrm{O}_{2}$ deficit ratio was observed between the two species after $2.5 \mathrm{~h}$ anoxia, with 30 ratios of $2.0 \pm 0.6$ (C. carpio) and $1.3 \pm 0.3$ (C. carassius). As predicted, lactate accumulation dynamics did sig- 31 nificantly differ between the species in both plasma and white muscle following anoxic exposure. Significant 32 lactate accumulation was seen in both plasma and muscle in C. carpio, but there was no accumulation of lac- 33 tate in white muscle tissue of $C$. carassius. These findings indicate that lactate accumulated as a consequence 34 of $2.5 \mathrm{~h}$ anoxic exposure is not a major determinant of the resulting EPHOC.
\end{abstract}

(C) 2013 Published by Elsevier Inc. 36

\section{Introduction}

Three cyprinid teleosts, the crucian carp (Carassius carassius (L)), goldfish (Carassius auratus (L)), and bitterling (Cyprinus amarus (Bloch)), are unique among vertebrates for their ability to convert lactate into ethanol as the end product of anaerobic metabolism (Shoubridge and Hochachka, 1980; Johnston and Bernard, 1983; Wissing and Zebe, 1988). The produced ethanol is freely diffusible over the cell membrane and is excreted from the fish via the gills (Shoubridge and Hochachka, 1980; van den Thillart et al., 1983; Stecyk et al., 2004). This rare adaptation is instrumental in a greatly enhanced tolerance to hypoxic conditions. Indeed, $C$. carassius can survive more than $24 \mathrm{~h}$ of anoxia at room temperature, and at least 4.5 months

Abbreviations/symbols: ADP, adenosine diphosphate; AMS, aerobic metabolic scope $\left(\mathrm{MO}_{2 \max } / \mathrm{MO}_{2 \text { std }}\right)$; ATP, adenosine triphosphate; EPHOC, excess post-hypoxic oxygen consumption ( $\mathrm{mg} \mathrm{O}_{2} \mathrm{~kg}^{-1}$ ); $\mathrm{MO}_{2 \max }$, maximal oxygen consumption rate $\left(\mathrm{mg} \mathrm{O}_{2} \mathrm{~kg}^{-1} \mathrm{~h}^{-1}\right.$ );

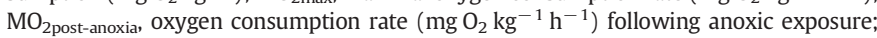
$\mathrm{MO}_{2 \text { std, }}$ standard metabolic rate $\left(\mathrm{mg} \mathrm{O}_{2} \mathrm{~kg}^{-1} \mathrm{~h}^{-1}\right) ; \mathrm{O}_{2 \text { sat, }}$ oxygen saturation (\%); $\mathrm{PCr}$ phosphocreatine; $\mathrm{S}_{\text {crit, }}$ critical oxygen saturation.

* Corresponding author. Tel.: +1 204474 8499; fax: +1 2044747604.

E-mail address: janet.genz@ad.umanitoba.ca (J. Genz).

Present address: Fisheries and Oceans Canada, Freshwater Institute, 501 University Crescent, Winnipeg, MB R3T 2N6, Canada. at near-zero temperatures (Holopainen and Hyvärinen, 1985; Piironen 53 and Holopainen, 1986; Nilsson and Renshaw, 2004). In contrast, the 54 common carp (Cyprinus carpio), a cyprinid species closely related to $C$. 55 carassius, does not possess the ability to produce ethanol (Nilsson, 56 1988), yet is regarded as a good anaerobe tolerating anoxic exposure 57 of at least $1 \mathrm{~h}$ at $20^{\circ} \mathrm{C}$ (van Waarde et al., 1990; van Raaij et al., 58 1996), and surviving less severe hypoxia $\left(0.5 \mathrm{mg} \mathrm{O}_{2} \mathrm{~L}^{-1}\right)$ for at least 59 7 days at $22-23{ }^{\circ} \mathrm{C}$ (Zhou et al., 2000).

The comparison of the hypoxia tolerance strategies between these 61 two species is based on the distinct differences in metabolic responses 62 to oxygen limitation each species employs. Standard metabolic rate 63 $\left(\mathrm{MO}_{2 \mathrm{std}}\right)$ is the minimum oxygen requirement for the maintenance of 64 unimpaired physiological reactions in postprandial unstressed animals 65 at rest. When the oxygen saturation $\left(\mathrm{O}_{2 \text { sat }}(\%)\right)$ in the water is too low 66 to support these basal requirements by aerobic metabolism, phospho- 67 creatine (PCr) acts as an "energy buffer", stabilizing the [ATP] by rapidly 68 regenerating ATP from ADP. The capacity to maintain the [ATP] by $\mathrm{PCr} 69$ hydrolysis is limited (van Ginneken et al., 1995; Dalla Via et al., 1997) 70 and anaerobic glycolysis is therefore the principal ATP-generating path- 71 way that can function during long periods of anoxia (Bickler and Buck, 72 2007). Due to the low ATP yield from anaerobic glycolysis, cells compen- 73 sate for the diminished aerobic energy production by a substantial 74 rise in glucose consumption rates resulting in lactate accumulation 75 (Hochachka, 1986). For every mole of glucosyl-units used to support 76 
anaerobic glycolysis, $2 \mathrm{~mol}$ of lactate is produced; deviations from a 2:1 ratio therefore indicate sources additional to glycogen depletion. This is the response to low oxygen saturation observed in most teleost fish species, including $C$. carpio. In conjunction with this process, $C$. carassius converts lactate into ethanol, which addresses the problem of acidification by ATP hydrolysis associated with lactate production (Hochachka and Mommsen, 1983) and, combined with one of the largest known glycogen stores of any vertebrate (Hyvärinen et al., 1985) allows $C$. carassius to maintain a relatively high glycolytic rate for extended periods (Nilsson, 1990). The conversion of lactate to ethanol in C. carassius happens exclusively in muscle tissue and lactate produced in tissues other than the muscle is transported via the blood to the muscle tissue for fermentation (Johnston and Bernard, 1983; Nilsson, 1988).

Fish can increase their oxygen consumption rate by several folds compared to $\mathrm{MO}_{2 \text { std }}$ until reaching their maximum capacity $\left(\mathrm{MO}_{2 \max }\right)$ wherein all aerobic activities are undertaken. During recovery from anoxia, oxygen consumption increases above $\mathrm{MO}_{2 \text { std }}$ for an extended period of time, but studies that quantify the total metabolic cost of recovery from severe hypoxia are rare (van den Thillart and Verbeek, 1991; Maxime et al., 2000; Svendsen et al., 2012). The accumulated excess post hypoxic oxygen consumption (EPHOC, $\mathrm{mg} \mathrm{O}_{2} \mathrm{~kg}^{-1}$ ) has classically been attributed to the lactate load, but evidence suggests that EPHOC is only partially related to the lactate load, and that resynthesis of glycogen from lactate during recovery is not the major component of the increased $\mathrm{O}_{2}$ consumption. Instead, the EPHOC has been attributed to re-synthesis of ATP and PCr in addition to glycogen, and also the buffering of protons generated from ATP utilization (van den Thillart and Verbeek, 1991; Virani and Rees, 2000; Mandic et al., 2008). However, the relative contributions of these processes to EPHOC in fish, and in particular the role of lactate, remain an area of ongoing investigation.

The present study examines the hypothesis that EPHOC associated with acute exposure to anoxia $\left(\leq 1 \% \mathrm{O}_{2 \text { sat }}\right.$ ) is positively correlated to lactate accumulation. Utilizing the close phylogenetic relationship, yet distinct difference in hypoxia tolerance physiology between $C$. carpio and C. carassius this study investigates the link between lactate load and EPHOC. Because lactate is converted to ethanol in $C$. carassius, but not in C. carpio, it was hypothesized that 1) acute exposure to anoxia would cause substantial lactate accumulation in C. carpio, while it would be limited in C. carassius; and 2) the lactate accumulation would result in greater EPHOC relative to the produced $\mathrm{O}_{2}$ deficit in $\mathrm{C}$. carpio, compared to $C$. carassius. In this study, we therefore quantified 1) concentration of lactate in muscle and plasma during exposure to anoxia in juvenile $C$. carassius and C. carpio, and 2) EPHOC $\left(\mathrm{mg} \mathrm{O}_{2} \mathrm{~kg}^{-1}\right)$ after exposure to $2.5 \mathrm{~h}$ anoxia.

\section{Materials and methods}

\subsection{Experimental animals}

A total of 34 juvenile $C$. carpio and 33 C. carassius $(110-130 \mathrm{~mm})$ were collected from a pond near Slagelse, Denmark (55 $17^{\prime} 58 \mathrm{~N}$ $11^{\circ} 27^{\prime} 47$ E) in April 2009. At capture water temperature was $12.5-14.0^{\circ} \mathrm{C}$. Fish were transferred to the University of Copenhagen, Marine Biological Laboratory, Helsingør, Denmark and kept indoors in a $400 \mathrm{~L}$ tank supplied with a continuous flow of unchlorinated tap water. Water was filtered using a mechanical filter pump (1100 $\mathrm{L} \mathrm{h}^{-1}$ ) connected to the tank, and water temperature was kept at $15 \pm 0.1{ }^{\circ} \mathrm{C}$ and continually aerated to maintain normoxic conditions. The fish were kept in a 12L:12D light regime and were fed to satiation 2-4 times per week with commercial fish pellets (Ecolife $3 \mathrm{~mm}$, Biomar, Denmark). Prior to experimentation, fish were acclimated to these conditions for 4 months. No fish was used more than once. All methods applied in the present study were in agreement with current Danish regulations for the treatment and welfare of experimental animals.

\subsubsection{Equipment setup}

The setup consisted of a static respirometer and a mixing pump sub- 141 merged in a $50 \mathrm{~L}$ opaque tank on a wet table, filled with unchlorinated 142 tap water maintained at $15 \pm 0.1{ }^{\circ} \mathrm{C}$. The respirometer was made of 143 transparent Perspex tubing and was fitted with two outlet and two 144 inlet ports. The mouth of the outlet tube, through which water left the 145 respirometer, was elevated slightly above the water surface level to pre- 146 vent the ambient water from entering the respirometer. Inside the res- 147 pirometer, a plate positioned $5 \mathrm{~mm}$ from the ports propagated water 148 mixing and prevented the fish from disturbing the inflow and outflow. 149 A perforated tube was inserted into the respirometer to minimize spon- 150 taneous activity associated with exposure to decreased $\mathrm{O}_{2 \text { sat }}$ levels, a 151 behavior that has been previously observed in C. carpio (Vianen et al., 152 2001). The tank was positioned behind a black curtain to minimize 153 stressful stimuli.

154

Measurements of $\mathrm{O}_{2}$ consumption rate $\left(\mathrm{MO}_{2} ; \mathrm{mg} \mathrm{O}_{2} \mathrm{~kg}^{-1} \mathrm{~h}^{-1}\right)$ were 155 carried out every 7 min 50 s using computerized intermittent-flow respi- 156 rometry allowing long term ( $>48 \mathrm{~h}$ ) repeated measurements as previ- 157 ously described (Steffensen et al., 1984; Steffensen, 1989). The repeated 158 respirometric loops consisted of a $3 \mathrm{~min} 20 \mathrm{~s}$ flushing phase during 159 which a pump flushed the respirometer with ambient water through 160 one set of ports. The second set of ports and a pump allowed the water 161 in the respirometer to be re-circulated in a closed circuit phase for 162 $4 \mathrm{~min} 30 \mathrm{~s}$, divided into a waiting period ( $2 \mathrm{~min}$ ) and a measurement pe- 163 $\operatorname{riod}(2 \min 30 \mathrm{~s})$.

Oxygen partial pressure was measured at $1 \mathrm{~s}^{-1}$ by a fiber optic 165 sensor (Fibox 3 connected to a dipping probe; PreSens, Regensburg, 166 Germany) located in the recirculated loop. The flush pump was con- 167 trolled by AutoResp software (Loligo Systems Aps, Tjele, Denmark) 168 that also calculated the oxygen consumption rate in the measuring 169 phase using the oxygen partial pressure and standard equations 170 (Schurmann and Steffensen, 1997). Preliminary testing demonstrated 171 that the duration of the measurement period ( 2 min $30 \mathrm{~s}$ ) in combi- 172 nation with the mass of the experimental fish $(19.5 \pm 0.7 \mathrm{~g})$ and the 173 volume of the respirometer and re-circulated loop $(0.335 \mathrm{~L})$ ensured 174 that the coefficient of determination $\left(\mathrm{r}^{2}\right)$ associated with the $\mathrm{MO}_{2} 175$ measurements was always $>0.90$ as in previous studies (Behrens 176 and Steffensen, 2007; Campbell et al., 2008). Moreover, in normoxia 177 the respiration of the fish never reduced the $\mathrm{O}_{2 \text { sat }}$ to less than $84 \% 178$ (approx. $17.5 \mathrm{kPa}$ ).

Water for the flush pump was supplied from one of two different 180 tanks containing either normoxic or hypoxic water maintained at 181 $15 \pm 0.1{ }^{\circ} \mathrm{C}$. Adequate water quality in the system was maintained 182 by an internal filter pump and an ultraviolet light sterilizer running 183 continually. Prior to initiation of an experiment the adjustable tank 184 was reduced to $\leq 2.5 \% \mathrm{O}_{2 \text { sat }}$ (approx. $0.5 \mathrm{kPa}$ ) by circulating water 185 from the tank through a vertical cylinder $(0.25 \mathrm{~m}$ in diameter, $1 \mathrm{~m} 186$ high) where the water was exposed to a stream of nitrogen bubbles 187 (Behrens and Steffensen, 2007). To minimize diffusion of $\mathrm{O}_{2}$ from 188 the ambient air, water surfaces were covered by floating bubblewrap. 189 The $\mathrm{O}_{2 \text { sat }}$ in the adjustable tank was measured using a Mini DO probe 190 (Loligo Systems Aps., Tjele, Denmark) connected to a relay that con- 191 trolled the $\mathrm{O}_{2 \text { sat }}$ in the tank via a solenoid valve regulating nitrogen 192 gas delivery to the cylinder similar to the procedure described by 193 (Jordan and Steffensen, 2007). The $\mathrm{O}_{2 \text { sat }}$ in the normoxic tank was 194 maintained at a constant high normoxic level ( $\geq 95 \% \mathrm{O}_{2 \text { sat }}$, approx. 195 $19.8 \mathrm{kPa}$ ) using air stones. The desired $\mathrm{O}_{2 \text { sat }}$ in the hypoxic tank was 196 adjusted and stabilized before the flush pump started supplying 197 water from this tank. In this way, the experiment was not influenced 198 by any delays caused by the time required to reduce the $\mathrm{O}_{2 \text { sat }}$ in the 199 hypoxic tank. The shift from normoxic to hypoxic water was made 200 by manually closing the valve regulating outflow from the normoxic 201 tank and opening the valve from the adjustable tank, which had 202 been previously brought to $\leq 2.5 \% \mathrm{O}_{2 \text { sat }}$ as described above. Both 203 
valves were situated outside the tank to eliminate disturbance of the fish, and preliminary tests confirmed that the procedure did not influence the metabolic rate of the fish. During the flush phase, the flush pump exchanged greater than 8 times the volume of water in the respirometer, which is sufficient to replace $>99 \%$ of the water (Steffensen, 1989). Using this arrangement, the $\mathrm{O}_{2 \text { sat }}$ inside the respirometer reached the designated $\mathrm{O}_{2 \text { sat }}$ level in $<3.5 \mathrm{~min}$ and was immediately followed by $\mathrm{MO}_{2}$ measurements.

\subsubsection{Experimental protocol of $\mathrm{MO}_{2}$ measurements}

EPHOC following anoxia was determined in two size-matched groups of 9 C. carpio $(19.5 \pm 1.1 \mathrm{~g})$ and 8 C. carassius $(19.5 \pm 0.7 \mathrm{~g})$. Fish were fasted for $24 \mathrm{~h}$ prior to experimentation. Individual $\mathrm{MO}_{2 \max }$ was tested in normoxia by transfer of the fish from the holding tank to a bucket and chasing to exhaustion, according to Richards et al. (2002). This protocol has been used to induce $\mathrm{MO}_{2 \max }$ in several teleost species as an alternative to swimming the fish in the respirometer (Peake and Farrell, 2006; Jordan and Steffensen, 2007; Killen et al., 2007). Upon exhaustion, identified by no further response to manual stimulation (after 5-6 min), fish were transferred to the respirometer where $\mathrm{MO}_{2}$ measurements were started immediately. After the $\mathrm{MO}_{2}$ max measurements, fish were acclimated to the respirometer for $24-48 \mathrm{~h}$.

Preliminary testing confirmed previous work that indicated the maximum survival time for $C$. carpio exposed to anoxia at $15^{\circ} \mathrm{C}$ was approx. $2.5 \mathrm{~h}$ (Stecyk and Farrell, 2002), and $2.5 \mathrm{~h}$ was consequently used as the duration of anoxic exposure. Tests with the two different species were carried out in random order. It was not possible to reduce the $\mathrm{O}_{2 \text { sat }}$ in the hypoxic tank to less than $2.5 \%$ ( $0.5 \mathrm{kPa}$ ). Therefore, to induce anoxia in the respirometer, the flush pump was turned off after the first flush period of the experiment. Shutting off the water exchange caused the fish to induce anoxia $\left(\leq 1 \% \mathrm{O}_{2 \text { sat }}\right.$ approx. $\left.0.2 \mathrm{kPa}\right)$ in the respirometer in $\leq 15 \mathrm{~min}$. After the anoxic exposure the flush pump was engaged and the respirometer flushed with normoxic water. Due to the lag time of the fiber optic sensor adjusting from $\leq 0.1$ to $>95 \%$ $\mathrm{O}_{2 \mathrm{sat}}$, the flush period of the first respirometric loop was extended by $3 \mathrm{~min}$ and the measurement discarded. Collection of $\mathrm{MO}_{2}$ data every $7 \mathrm{~min}$ and $50 \mathrm{~s}$ continued for $>12 \mathrm{~h}$ after the exposure to anoxia.

\subsubsection{Acquisition and analysis of respirometry data}

Because of the rapid turnover of water, both the exact rate of change of the $\mathrm{O}_{2 \text { sat }}$ and the response time of the $\mathrm{O}_{2}$ consumption rate of the fish were unknown during the flush periods; because of these uncertainties the flush periods used to modify the $\mathrm{O}_{2 \text { sat }}$ inside the respirometer were not included in the calculations. $\mathrm{MO}_{2 \text { std }}$ was defined as the mean of the last seven measurements ( 54 min $50 \mathrm{~s}$ ) (Fig. 1) before onset of hypoxia, similar to previously employed procedures (Scarabello et al., 1991; Svendsen et al., 2010). The EPHOC protocol involved rapid changes of

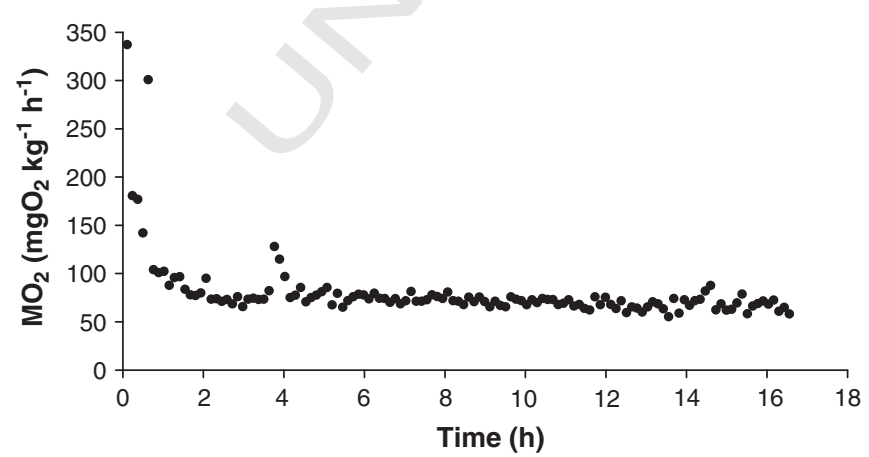

Fig. 1. Representative trace of the time course of $\mathrm{MO}_{2}$ measurements $\left(\mathrm{mg} \mathrm{O}_{2} \mathrm{~kg}^{-1} \mathrm{~h}^{-1}\right)$ during acclimation in a static respirometer. Data were collected using a $23.7 \mathrm{~g}$ common carp (Cyprinus carpio) at $15^{\circ} \mathrm{C}$. Each datum represents a $7 \mathrm{~min} 50 \mathrm{~s}$ period. $\mathrm{MO}_{2}$ is corrected for background respiration. the $\mathrm{O}_{2 \text { sat }}$ inside the respirometer during single flush periods (from 250 normoxia to anoxia and vice versa). The oxygen deficit $\left(\mathrm{mg} \mathrm{O}_{2} \mathrm{~kg}^{-1}\right) 251$ accumulated during the anoxic period was quantified as the $\mathrm{MO}_{2 \text { std }}$ dur- 252 ing the $2.5 \mathrm{~h}$. Individual recovery periods were regarded as completed 253 when the first $\mathrm{MO}_{2}$ datum in the post anoxia recovery period $\left(\mathrm{MO}_{2}-254\right.$ post-anoxia) was within a $95 \%$ confidence interval $(\mathrm{Cl})$ of the $\mathrm{MO}_{2 \text { std }} 255$ (Fig. 2) as previously described (Bushnell et al., 1994; Svendsen et al., 256 2010). The metabolic cost of recovery $\left(\mathrm{mg} \mathrm{O}_{2} \mathrm{~kg}^{-1}\right)$ was determined 257 by subtracting the $\mathrm{MO}_{2 \text { std }}$ from $\mathrm{MO}_{2}$ post-anoxia, following Jordan and 258 Steffensen (2007). Aerobic metabolic scope was calculated as the differ- 259 ence between $\mathrm{MO}_{2 \max }$ and $\mathrm{MO}_{2}$ std, following Farrell and Richards 260 (2009).

\subsection{Measurements of plasma and muscle lactate}

\subsubsection{Equipment setup}

Two groups of 25 size matched $C$ carpio and C carassius $(20.9 \pm 0.5$ plasma and white muscle. A 180 L aquarium was fitted with black plastic 266 on all sides to prevent visual disturbance, filled with unchlorinated tap 267 water, and fitted with an internal filter pump to ensure adequate mixing. 268 The temperature was kept at $15 \pm 0.1{ }^{\circ} \mathrm{C}$ and the water was maintained 269 normoxic by continuous aeration by air stones. The $\mathrm{O}_{2 \text { sat }}$ was monitored 270 using a Mini DO probe (Oxyguard International, Birkerød, Denmark) 271 connected to a relay controlling the $\mathrm{O}_{2 \text { sat }}$ in the tank via a solenoid 272 valve that regulated nitrogen gas delivery to multiple air stones on the 273 bottom of the aquarium. All holes around tubes and cables into the 274 aquarium were covered with plastic film. The sealed container facilitated 275 precise regulation of $\mathrm{O}_{2 \text { sat }}$ from $\geq 95 \%$ to $1 \%$. To allow individual sampling 276 with a minimum of disturbance of the remaining fish in the aquarium, 277 each fish was inserted in a small cage made from plastic mesh tube 278 (40 mm diameter). A nylon string was fitted to each cage and a small 279 weight kept the cage on the bottom and made it impossible for the fish 280 to move the cage.

\subsubsection{Experimental protocol of lactate sampling}

Fish were starved for $24 \mathrm{~h}$ before being transferred from the hold- 283 ing tank to the aquarium and inserted in the cages. Acclimation to the 284 aquarium under normoxia lasted for $36 \mathrm{~h}$, and fish were not fed dur- 285 ing this time. Five fish of each species were sampled immediately be- 286 fore the onset of hypoxia as a normoxic baseline. Within $1 \mathrm{~h}$ anoxia 287 was reached $\left(1 \pm 0.2 \% \mathrm{O}_{2 \text { sat }}\right.$, approx. $\left.0.2 \mathrm{kPa}\right)$ by nitrogen bubbling. 288 Subsequently, a fish was sampled every 4 min. Alternating between 289

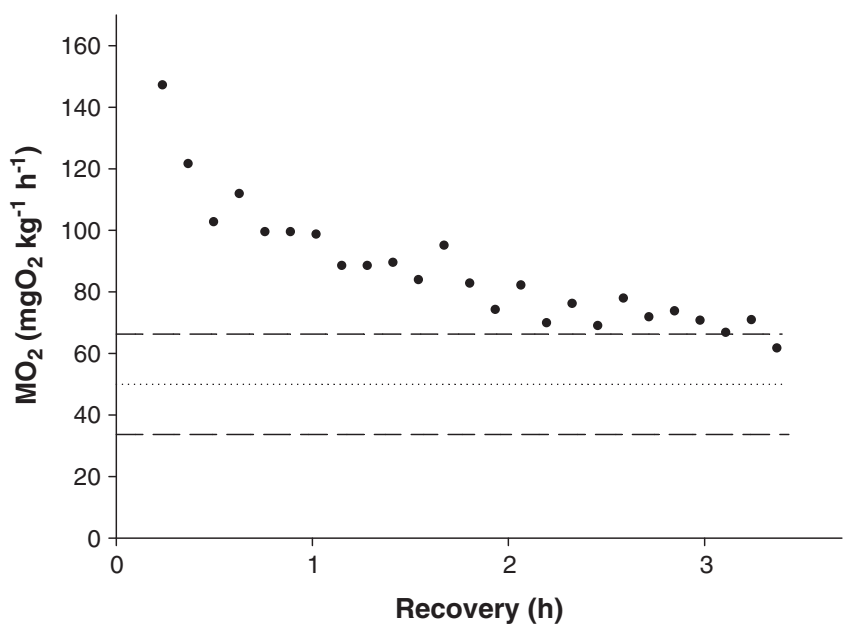

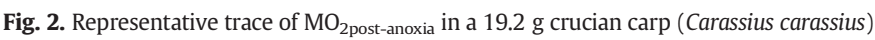
after $2.5 \mathrm{~h}$ anoxia exposure. $\mathrm{MO}_{2 \text { std }} \pm 95 \% \mathrm{CI}$ are illustrated using a dotted and two dashed lines, respectively. $\mathrm{MO}_{2}$ is corrected for background respiration. The first $\mathrm{MO}_{2}$ datum in the post anoxia recovery period within the $95 \%$ confidence interval $(\mathrm{CI})$ of the $\mathrm{MO}_{2 \mathrm{std}}$ was used as the marker indicating completion of the recovery period. 
each species, a total of $20 \mathrm{C}$. carpio and $20 \mathrm{C}$. carassius were sampled, giving a total anoxic exposure period of $2 \mathrm{~h} 40 \mathrm{~min}$.

At sampling, the lid was lifted slightly and a cage retracted from the tank by the nylon string. The cage was immediately transferred to a $2.5 \%$ benzocaine solution (Sigma-Aldrich Chemicals, USA) made from a $4 \%$ ethanol stock solution. At complete anesthesia ( $\leq 1 \mathrm{~min}$ ), the fish were removed from the cages, patted dry and weighed to the nearest $0.1 \mathrm{~g}$. Blood samples were collected by severing the tail from the body and collecting the blood flowing from the caudal vein with a heparinized $1 \mathrm{~mL}$ syringe (LEO Pharma A/S, Ballerup, Denmark). The blood sample was transferred to a $0.5 \mathrm{~mL}$ centrifuge tube and centrifuged at $2000 \mathrm{~g}$ for $30 \mathrm{~s}$ to isolate the plasma. A tissue sample was taken as a cross section of the trunk musculature posterior to the dorsal fin and wrapped in an aluminum foil. Both the tissue and plasma samples were flash frozen in liquid $\mathrm{N}_{2}$ and stored at $-80{ }^{\circ} \mathrm{C}$ until analysis.

\subsubsection{Determination of lactate concentration}

Extraction of lactate from the tissue samples was carried out following procedures previously described (Viant et al., 2003; Lin et al., 2007). The frozen muscle samples were ground to a fine powder in a $\mathrm{N}_{2}$-cooled mortar. The frozen, powdered tissue $(100 \mathrm{mg})$ was weighed in a $\mathrm{N}_{2}$-cooled $1.5 \mathrm{~mL}$ centrifuge tube and extracted using $5 \mathrm{~mL} \mathrm{~g}^{-1}$ (wet mass) ice cold $6 \%$ perchloric acid. Samples were kept on ice throughout the extraction procedure. Samples were vortexed for $15 \mathrm{~s}$ three times, centrifuged $\left(10,000 \mathrm{~g}, 10 \mathrm{~min}, 4^{\circ} \mathrm{C}\right)$, and the supernatant was removed and neutralized to $\mathrm{pH} 7.5$ with $2 \mathrm{M} \mathrm{K}_{2} \mathrm{CO}_{3}$, testing $\mathrm{pH}$ using small drops of sample on $\mathrm{pH}$ paper ( $\mathrm{pH}$ paper range: 5.5-9.0). Samples were kept on ice for an additional $30 \mathrm{~min}$ to facilitate complete precipitation. Following centrifugation $\left(10,000 \mathrm{~g}, 10 \mathrm{~min}, 4^{\circ} \mathrm{C}\right)$, the supernatant was removed and stored at $-80{ }^{\circ} \mathrm{C}$. Muscle extracts and plasma were analyzed for lactate using a commercial kit (Biomedical Research Service, NY, USA). The measurements were corrected using internal lactate standards in samples from fish of both species sampled in normoxic conditions.

\subsection{Statistical analysis}

All values are reported as mean \pm standard error of the mean (SEM). Means were compared using Student's t-test (two-tailed) after testing the assumptions of normal distribution of data and homogeneity of variance. Means of data found not to be normally distributed were compared using the Mann-Whitney test. Least square linear regression analysis was performed using SigmaPlot 10.0 (Systat Software Inc. San Jose, CA, USA), and regression line slopes were compared using analysis of covariance. Statistical analyses were carried out using SPSS 15.0 (IBM SPSS, Armonk, NY, USA). Means were considered significantly different when $\mathrm{P}<0.05$.

\section{Results}

\subsection{Oxygen consumption rates}

$\mathrm{MO}_{2}$ std differed significantly between $C$. carassius and C. carpio (Table $1, \mathrm{P}<0.02$ ). Similarly, $\mathrm{MO}_{2 \max }$ in $C$. carassius was significantly lower than the $\mathrm{MO}_{2 \max }$ measured in $C$. carpio $(\mathrm{P}<0.0001)$. Despite the overall greater oxygen consumption seen in $C$. carpio, aerobic metabolic scope (AMS, $\mathrm{MO}_{2 \mathrm{max}} / \mathrm{MO}_{2 \text { std }}$ ) did not differ between these two species $(\mathrm{P}>0.8)$. As a consequence of the different $\mathrm{MO}_{2 \text { std }}$ the accumulated $\mathrm{O}_{2}$ deficit during the anoxic period was greater in C. carpio than $C$. carassius $(\mathrm{P}<0.02)$, and there was also a significant difference in EPHOC $(\mathrm{P}<0.02)$. Although both EPHOC and $\mathrm{O}_{2}$ deficit were lower in C. carassius than C. carpio, the ratio of EPHOC: $\mathrm{O}_{2}$ deficit did not differ between species $(P>0.48)$. The average time to complete metabolic recovery was longer for $C$. carpio $(7.0 \pm 1.4 \mathrm{~h})$ than for $C$. carassius $(3.8 \pm 0.7 \mathrm{~h})(\mathrm{P}<0.034)$. As was the case with the
Table 1

$\mathrm{t} 1.1$

Observations of metabolic parameters in normoxia and during recovery from $2.5 \mathrm{~h}$ acute t1.2 anoxic exposure in crucian carp (Carassius carassius, $\mathrm{n}=8,19.5 \pm 0.6 \mathrm{~g}$ ) and common t1.3 carp (Cyprinus carpio, $\mathrm{n}=9,19.5 \pm 1.1 \mathrm{~g}$ ) at $15^{\circ} \mathrm{C}$. Asterisks indicate significant differences t1.4 between species using two tailed Student's $t$-test, ${ }^{*} \mathrm{P}<0.05$; and ${ }^{* * *} \mathrm{P}<0.0001$; NS, not t1.5 significant.

\begin{tabular}{|c|c|c|c|}
\hline & C. carassius & C. carpio & $\mathrm{P}$ \\
\hline $\mathrm{MO}_{2 \text { standard }}\left(\mathrm{mg} \mathrm{O}_{2} \mathrm{~kg}^{-1} \mathrm{~h}^{-1}\right)$ & $43.7 \pm 5.3$ & $66.5 \pm 6.2$ & $*$ \\
\hline $\mathrm{MO}_{2 \max }\left(\mathrm{mg} \mathrm{O} \mathrm{Og}^{-1} \mathrm{~h}^{-1}\right)$ & $213.7 \pm 7.3$ & $329.5 \pm 10.3$ & $* * *$ \\
\hline AMS $\left(\mathrm{MO}_{2 \max } / \mathrm{MO}_{2 \mathrm{std}}\right)$ & $5.2 \pm 0.4$ & $5.4 \pm 0.6$ & NS \\
\hline $\mathrm{O}_{2}$ deficit $\left(\mathrm{mg} \mathrm{O}_{2} \mathrm{~kg}^{-1}\right)$ & $108.5 \pm 13.1$ & $164.9 \pm 15.5$ & $*$ \\
\hline EPHOC $\left(\mathrm{mg} \mathrm{O}_{2} \mathrm{~kg}^{-1}\right)$ & $124.4 \pm 18.9$ & $281.1 \pm 53.5$ & * \\
\hline EPHOC: $\mathrm{O}_{2}$ deficit & $1.3 \pm 0.3$ & $2.0 \pm 0.6$ & NS \\
\hline Time to recovery $(\mathrm{h}$ ) & $3.8 \pm 0.7$ & $7.0 \pm 1.4$ & $*$ \\
\hline$\%$ of $\mathrm{MO}_{2 \max }$ & $65.4 \pm 8.3$ & $61.6 \pm 7.6$ & NS \\
\hline
\end{tabular}

AMS, the utilized metabolic scope was similar for the two species, 350 and during the recovery phase neither of the species utilized their 351 full metabolic scope, with the highest measurements of $\mathrm{MO}_{2} 352$ representing $65.4 \pm 8.3 \%$ of $\mathrm{MO}_{2 \max }$ in $\mathrm{C}$. carassius and $61.6 \pm 7.6 \%$ in 353 C. carpio $(\mathrm{P}>0.7)$.

\subsection{Lactate accumulation}

355

Parameters describing the production and accumulation of lactate 356 during anoxic exposure are summarized in Table 2. Concentrations of lac- 357 tate prior to anoxic exposure did not differ between species in plasma 358 $(3.8 \pm 0.5$ in C. carassius vs. $3.3 \pm 0.4 \mathrm{mM}$ in C. carpio, $\mathrm{P}>0.48)$ nor muscle 359 $\left(2.1 \pm 0.1\right.$ vs. $\left.1.7 \pm 0.3 \mu \mathrm{mol} \mathrm{g}^{-1} ; \mathrm{P}>0.26\right)$. While the lactate concentra- 360 tion in the plasma rose significantly in both species, in the muscle tissue 361 the concentration of lactate increased only in C. carpio (Fig. 3). In conse- 362 quence the accumulation of lactate in C. carassius was significantly higher 363 in plasma than in muscle $(\mathrm{P}<0.0001)$, with plasma [lactate] increasing 3364 fold to $12 \mathrm{mmol} \mathrm{L}^{-1}$ (Table 2, Fig. 3A). C. carpio plasma [lactate] increased 365 6 fold to $21 \mathrm{mmol} \mathrm{L}^{-1}$, and in contrast to $C$. carassius the lactate accumu- 366 lation in plasma was significantly higher than in muscle $(\mathrm{P}<0.0001 ; 367$ Table 2), with muscle [lactate] increasing 5 fold to a final concentration 368 of $8.97 \mu \mathrm{mol} \mathrm{g}^{-1}$ (Table 2, Fig. 3B). The lactate accumulation was faster 369 in C. carpio than in C. carassius in both plasma $\left(\mathrm{mmol} \mathrm{L}^{-1} \mathrm{~h}^{-1}, \mathrm{P}<0.01\right) 370$ and muscle $\left(\mu \mathrm{mol} \mathrm{g}{ }^{-1} \mathrm{~h}^{-1}, \mathrm{P}<0.01\right)$.

\section{Discussion}

\subsection{Respirometry}

\subsubsection{Extent of EPHOC in various species}

374

To our knowledge, EPHOC following exposure to oxygen levels below 375 $\mathrm{S}_{\text {crit }}$ has been quantified for only three other fish species: C. auratus (van 376 den Thillart and Verbeek, 1991) Scophthalmus maximus (Maxime et al., 377 2000), and Oncorhynchus mykiss (Svendsen et al., 2012). Several species 378 of flatfish are moderately hypoxia tolerant (Dalla Via et al., 1994; 379 Pichavant et al., 2002), and in hypoxia trials on S. maximus, a benthic flat- 380 fish found in temperate seas, the EPHOC: $\mathrm{O}_{2}$ deficit ratio was 16:1 381 (Maxime et al., 2000), which is only half of the ratio of up to $35: 1$ ob- 382 served in the hypoxia intolerant rainbow trout (O. mykiss) (Svendsen et 383

\section{Table 2}

Lactate development during $2.7 \mathrm{~h}$ acute anoxic exposure at $15{ }^{\circ} \mathrm{C}$ in crucian carp t2.2 (Carassius carassius) and common carp (Cyprinus carpio) $(20.8 \pm 0.5 \mathrm{~g}$ combined mean $\mathrm{t} 2.3$ body mass). Concentrations at $2.5 \mathrm{~h}$ anoxia were calculated from the linear regression $\mathrm{t} 2.4$ $\begin{array}{lr}\text { (see Fig. 3). Asterisks }\left({ }^{*}\right) \text { indicate statistical differences between species }(\mathrm{P}<0.01) . & \mathrm{t} 2.5\end{array}$

\begin{tabular}{|c|c|c|c|c|c|c|c|}
\hline \multirow[t]{2}{*}{ Lactate parameters } & \multicolumn{3}{|c|}{ Plasma $\left(\mathrm{mmol} \mathrm{L}^{-1}\right)$} & \multicolumn{3}{|c|}{ Muscle $\left(\mu \mathrm{mol} \mathrm{g}{ }^{-1}\right)$} & $\mathrm{t} 2.6$ \\
\hline & C. carassius & C. carpio & $\mathrm{P}$ & C. carassius & C. carpio & $P$ & $\mathrm{t} 2.7$ \\
\hline Normoxia & $3.8 \pm 0.5$ & $3.3 \pm 0.4$ & NS & $2.1 \pm 0.1$ & $1.7 \pm 0.3$ & NS & $\mathrm{t} 2.8$ \\
\hline $2.5 \mathrm{~h}$ anoxia & 12.0 & 20.9 & - & 2.6 & 9.0 & - & $\mathrm{t} 2.9$ \\
\hline Increase (fold) & 3.16 & 6.33 & - & 1.23 & 5.28 & - & $\mathrm{t} 2.10$ \\
\hline Slope $\left(\mathrm{h}^{-1}\right)$ & $1.45 \pm 0.45$ & $3.92 \pm 0.82$ & * & $0.05 \pm 0.18$ & $1.20 \pm 0.41$ & * & $\mathrm{t} 2.11$ \\
\hline
\end{tabular}



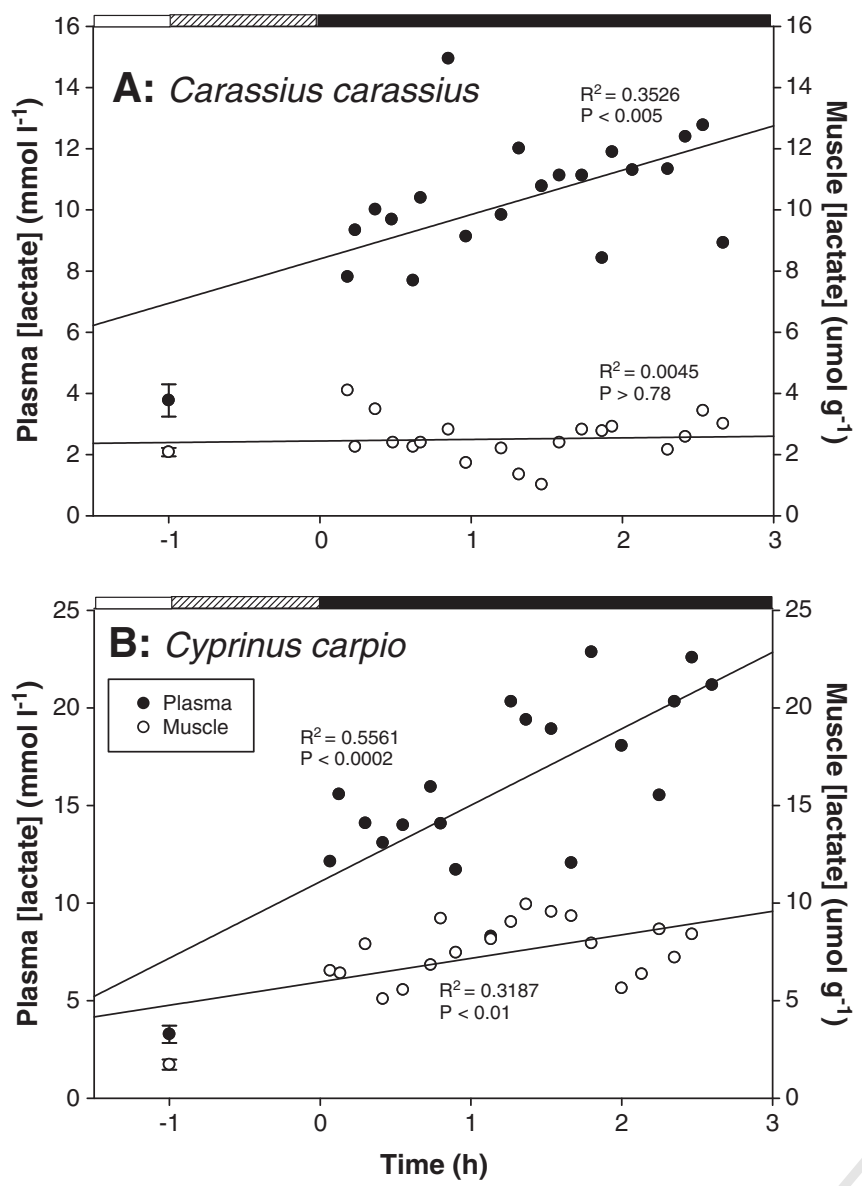

Fig. 3. Linear accumulation of lactate in plasma ( $\mathrm{mmol} \mathrm{L}^{-1}$, black) and muscle $\left(\mu \mathrm{mol} \mathrm{g}{ }^{-1}\right.$ white) in A: crucian carp (Carassius carassius, $20.3 \pm 0.6 \mathrm{~g}$ ) and B: common carp (Cyprinus carpio, $21.4 \pm 0.8 \mathrm{~g}$ ) prior to and during $2.5 \mathrm{~h}$ of anoxia. The white bar indicates the normoxia $\left(>95 \% \mathrm{O}_{2 \text { sat }}\right)$ period, the hatched bar indicates the period with decreasing $\mathrm{O}_{2 \text { sat, }}$ and the black bar indicates the anoxia period ( $\leq 1 \% \mathrm{O}_{2 \text { sat }}$ ), beginning at $0 \mathrm{~h}$. Each datum represents a measurement on one fish in the anoxia period, except at $t=-1$, which is the mean $\pm S E M$ of fish sampled in normoxia $(n=5)$. Linear regressions are represented by the following equations: C. carassius plasma $\mathrm{y}=1.4499 \mathrm{x}+8.3973$, and muscle $\mathrm{y}=0.0511 \mathrm{x}+2.4467 ;$ C carpio plasma $\mathrm{y}=3.9176 \mathrm{x}+11.0967$, and muscle $\mathrm{y}=1.2026 \mathrm{x}+5.9680$.

al., 2012), but still an EPHOC: $\mathrm{O}_{2}$ deficit ratio far greater than the ratios determined for both $C$. carassius and C. carpio in the present study (1.3:1 and $2.0: 1$, respectively), and of approximately $1.5: 1$ observed in C. auratus (van den Thillart and Verbeek, 1991). Of the fish species so far investigated for EPHOC, it is interesting to note that the species that accumulate only minimal oxygen debt are all members of the Cyprinidae. Of even greater interest, this capability does not seem to depend entirely on the ability to produce ethanol, as $C$. carpio demonstrates substantially lower EPHOC: $\mathrm{O}_{2}$ deficit than other non-ethanol-producing species, but an approximately equivalent deficit to ethanol-producing $C$. carassius and C. auratus.

The observed EPHOC: $\mathrm{O}_{2}$ debt ratio in $\mathrm{C}$. carassius of 1.3:1 following $2.5 \mathrm{~h}$ anoxia at $15{ }^{\circ} \mathrm{C}$ (Table 1 ) is quite similar to the results obtained for the closely related species C. auratus (van den Thillart and Verbeek, 1991), which showed an EPHOC: $\mathrm{O}_{2}$ deficit ratio of 1.5:1 after $12 \mathrm{~h}$ of anoxia at $20^{\circ} \mathrm{C}$. However EPHOC in the goldfish (C. auratus) was not observed following $3 \mathrm{~h}$ of anoxia, (van den Thillart and Verbeek, 1991) requiring greater time and temperature than those needed for EPHOC to be recorded in C. carassius. The fact that we did observe an EPHOC in $C$. carassius after the relatively short $2.5 \mathrm{~h}$ anoxia exposure could be attributed to the following factors: 1 ) species-specific physiological differences, despite the fish belonging to the same genus, 2) difference in the timescale of changing $\mathrm{O}_{2 \text { sat }}$ levels and hence time for adjusting ventilatory and cardiac response as well as for the initiation of metabolic depression, 3) an overestimate of the resting metabolic rate in the pre- 408 vious study, thereby "hiding" the EPHOC, or 4) metabolic suppression 409 continuing after reestablishment of normoxia. In addition to the conver- 410 sion of lactate to ethanol, $C$. carassius, unlike C. carpio, can also depress 411 its metabolism; van Ginneken and van den Thillart (2009) demonstrat- 412 ed that metabolic depression in C. auratus was initiated within 413 20-30 min after reduction of environmental $\mathrm{O}_{2 \text { sat }}$, and additionally 414 that 1-2 h was needed to accomplish the full metabolic depression 415 (by approximately $70 \%$ from $\mathrm{MO}_{2 \mathrm{std}}$ ). In van den Thillart and 416 Verbeek's (1991) study discussed above, in which EPHOC did not 417 occur following $3 \mathrm{~h}$ anoxia, complete anoxia was not reached until 418 after approximately $2.5 \mathrm{~h}$, giving the goldfish sufficient time to reach 419 full metabolic depression before anoxia was reached. In the present 420 study, anoxia was reached in $<30 \mathrm{~min}$, and in consequence, C. carassius 421 would only have been able to take full advantage of the ability to depress 422 metabolism for approximately the last hour of the exposure. Regardless 423 of the reason for this difference between our results and the observa- 424 tions by van den Thillart and Verbeek (1991), a very small EPHOC in C. 425 Q2 carassius was observed in the present study, indicating comparatively 426 higher hypoxia tolerance than is observed in C. carpio and other fish 427 species.

\subsubsection{Small and uniform EPHOC in Cyprinidae}

The oxygen deprivation utilized in this study was at a near lethal 430 level for C. carpio (Johnston and Bernard, 1983; van der Linden et 431 al., 2001; Stecyk and Farrell, 2002) but should be easily tolerated by 432 C. carassius, yet no difference in the ratio of EPHOC: $\mathrm{O}_{2}$ was found be- 433 tween the two species (Table 1). Interestingly, both species only in- 434 creased metabolic rate to approximately $60 \%$ of their $\mathrm{MO}_{2 \max }$ in the 435 recovery period and for a relatively short period of time (4-7 h), 436 given the length of the exposure.

During anoxia, ATP levels in the brain of C. carpio slowly decrease 438 (van Ginneken et al., 1996) and a significant swelling of the brain is 439 seen over time due to the inactivation of the ATP dependent pumps 440 regulating cell volume (Nilsson, 2001; van der Linden et al., 2001). 441 These physiological responses to anoxia cause $C$. carpio to in essence 442 slowly die during anoxia, while $C$. carassius is protected from such ef- 443 fects. Hallman et al. (2008) showed that $C$. carpio have a fairly large 444 capacity for maintaining ATP levels using $\mathrm{PCr}$ as a buffer during $\mathrm{O}_{2} 445$ levels below $\mathrm{S}_{\text {crit }}$ (approx. 13\% $\mathrm{O}_{2 \text { sat }}$ or $2.7 \mathrm{kPa}$ ). During this exposure 446 it took approximately $2 \mathrm{~h}$ to reduce the [PCr] by half. Over the same 447 timespan only a minor rise in plasma lactate took place in white mus- 448 cle, indicating that $C$. carpio preferentially uses its $\mathrm{PCr}$ reserves before 449 initiating the fermentation pathway for ATP resynthesis, presumably 450 as an attempt to reduce metabolic acidification (Hochachka and 451 Mommsen, 1983; van den Thillart and van Waarde, 1993).

In C. carpio (Hallman et al., 2008) as well as C. auratus (Mandic et al., 453 2008 ) both $\mathrm{pH}$ and $\mathrm{PCr}$ are completely recovered before lactate recovers. 454 Despite high lactate loads remaining during recovery from exercise, fish 455 can perform strenuous exercise at pre-fatigue levels when excess 456 post-exercise oxygen consumption is repaid (Brett, 1964). This suggests 457 that the acidification from the fermentation of glucose is likely of greater 458 importance for the EPHOC than the lactate load itself. Indeed, in C. auratus 459 (van den Thillart and Verbeek, 1991) and C. carassius (present study) the 460 accumulation of lactate per se does not appear to burden the fish, and 461 seems only to have a limited impact on the EPHOC in the two species 462 at shorter timescales. A lactate-independent EPHOC could also indicate 463 that $C$. carpio may have evolved to be able to cope with high lactate 464 loads through residence in eutrophic habitats that experience regular 465 hypoxic events (e.g. during the night). High amounts of stored lactate 466 could subsequently be converted to glucose for aerobic respiration. Lac- 467 tate is an excellent substrate for oxidation, and lactate in the blood can 468 be metabolized by the heart, kidney and gills during period of high oxy- 469 gen levels, or used for glyconeogenesis in situ. By not having to produce 470 glycogen from the accumulated lactate, $C$. carpio would only have to 471 
repay an EPHOC corresponding to the required regeneration of ATP, $\mathrm{PCr}$ and internal $\mathrm{O}_{2}$ stores (Scarabello et al., 1991).

Unique to ethanol producing species is the extensive loss of carbonic molecules due to anaerobic metabolism. C. auratus excrete $80 \%$ of the ethanol produced (van den Thillart and Verbeek, 1991) during anoxia, and continues to excrete significant amounts of ethanol for several hours after return to normoxic conditions (Mandic et al., 2008), indicating that lactate is preferentially converted to ethanol, even under normoxic conditions. If similar processes occur in C. carassius, accumulated lactate would have a minor influence on the EPHOC and it follows that the observed EPHOC from the duration of anoxia examined here $(2.5 \mathrm{~h})$ would mainly consist of regeneration of ATP, $\mathrm{PCr}$ and internal $\mathrm{O}_{2}$ stores in a similar way as C. carpio, with limited remaining substrate for either Cori cycle or in situ glyconeogenesis. This may, at least in part, explain the observed similarity of the EPHOC despite significantly different lactate loads and diverse physiology between $C$. carpio and C. carassius. Further investigation of $\mathrm{pH}$, lactate, ethanol, $\mathrm{PCr}$ and ATP dynamics during anoxia and recovery is needed, in combination with $\mathrm{MO}_{2}$ measurements, to shed light on the cause of this unexpected observation of small and uniform EPHOC: $\mathrm{O}_{2}$ deficit in $\mathrm{C}$. carassius and C. carpio.

\subsection{Lactate}

\subsubsection{Diverse lactate accumulation}

As predicted, there was a difference in the pattern of lactate accumulation between C. carpio and C. carassius. Both plasma and muscle [lactate] rose significantly in C. carpio, but in C. carassius only plasma [lactate] increased (Table 2). Our measurements in muscle of $C$. carassius (Table 2) indicate no accumulation over normoxic values, which can be attributed to the short duration of anoxic exposure. In this species [lactate] the muscle increases approximately 4 fold following 6 h anoxia, yet no accumulation is seen following $3 \mathrm{~h}$ progressive hypoxia (Johnston and Bernard, 1983). The magnitude of lactate accumulation in the plasma also differed between species, with $C$. carpio accumulating almost twice as much lactate in plasma (Table 2), indicating a larger glycolytic flux in C. carpio.

\subsubsection{High plasma lactate concentrations}

C. carpio exerting moderate levels of exercise maintain levels of plasma [lactate] of approximately $1.5 \mathrm{mmol} \mathrm{L}^{-1}$ (van Ginneken et al., 2004a), which is similar to that measured in the present study (Table 2). However, both $C$. carpio and $C$. carassius completely at rest in normoxia have only $0.2-0.5 \mathrm{mmol} \mathrm{L}^{-1}$ lactate in the plasma (Holopainen et al., 1986; Vianen et al., 2001) at $20^{\circ} \mathrm{C}$ and $18{ }^{\circ} \mathrm{C}$, respectively, indicating that the fish in this study (at $15^{\circ} \mathrm{C}$ ) were most likely exhibiting some spontaneous activity prior to sacrifice for lactate quantification, despite efforts to limit this activity. Following anoxic exposure, the accumulated plasma [lactate] in C. carpio $\left(20.9 \mathrm{mmol} \mathrm{L}^{-1}\right)$ is also higher than reported in other studies of carp exposed to hypoxia. Vianen et al. (2001) measured 6-13 $\mathrm{mmol} \mathrm{L}^{-1}$ in plasma of cannulated C. carpio after 6 h progressive severe hypoxia. In C. carassius, plasma [lactate] increased approximately 3-fold to $12 \mathrm{mmol} \mathrm{L}^{-1}$, demonstrating a similar qualitative response to anoxia as in previous studies where plasma [lactate] doubled following anoxic exposure (Holopainen et al., 1986).

There are two probable explanations for the high plasma [lactate] after exposure to anoxia. Firstly, the quick entry into anoxia $(\sim 1 \mathrm{~h}) \mathrm{di}-$ rectly from normoxia, compared to a gradual transition that allows for metabolic depression before entry into hypoxia. Change in $\mathrm{O}_{2 \text { sat }}$ over only $1 \mathrm{~h}$ might be too fast to ensure sufficient time to initiate metabolic depression (van Ginneken and van den Thillart, 2009) or adequate ventilatory and cardiac responses (van Ginneken et al., 2004b; Wilkie et al., 2008), creating a higher $S_{\text {crit }}$, and forcing initiation of anaerobic metabolism earlier than if extraction capacity was able to be adjusted during the $\mathrm{O}_{2 \text { sat }}$ decrease. Second, the metabolic stress during anoxia caused by relying exclusively on anaerobic metabolism may produce additional lactate accumulation, compared to the scenario in hypoxia where some aerobic metabolism can be maintained. In an Amazonian cichlid, Astronotus ocellatus, the lactate 535 accumulation was 5 fold higher at $6 \% \mathrm{O}_{2 \text { sat }}$ than at $10 \% \quad \mathrm{O}_{2 \text { sat }} 536$ (Muusze et al., 1998) and in Solea solea a 4-5 fold higher accumula- 537 tion at $6 \% \mathrm{O}_{2 \text { sat }}$ than at $12 \% \mathrm{O}_{2 \text { sat }}$ was observed (Dalla Via et al., 538 1994). This illustrates how the shift to complete reliance on anaerobic 539 metabolism happens relatively swiftly when anoxia is approached, 540 and why data obtained in different levels of hypoxia remain difficult 541 to compare.

542

Both species considered in this study demonstrated higher [lac- 543 tate] in plasma compared to muscle. This may be a distinguishing fac- 544 tor for lactate accumulation due to hypoxia. For example the response 545 of $S$. solea to severe hypoxia is qualitatively similar to our observa- 546 tions in C. carpio (Dalla Via et al., 1994), however, during exercise in 547 S. solea the pattern is quite different, with the majority of lactate 548 being produced and subsequently retained in the working muscles, 549 resulting in lactate concentrations in muscle that are several folds 550 higher in muscle than in plasma (Dalla Via et al., 1997). This is an ad- 551 vantage in normoxia due to the higher buffer capacity of the muscle 552 tissue and because any acidification of the blood will lead to lowering 553 of the hemoglobin binding affinity reducing $\mathrm{O}_{2}$ extraction capacity, 554 which is likely to prolong the duration of recovery. Indeed, accumula- 555 tion of lactate in both the plasma and muscle tissue of $C$. carpio, but 556 not $C$. carassius, coincides with significantly longer metabolic recov- 557 ery (Table 1 ).

\subsubsection{Impact of ethanol production on lactate accumulation}

The ethanol production in C. carassius is well described (Johnston 560 and Bernard, 1983) and is evident in the present study by the complete 561 absence of accumulation of lactate in muscle tissue of $C$. carassius. Un- 562 like in C. carpio, ATP levels in C. carassius are not primarily maintained 563 by $\mathrm{PCr}$ stores. Mandic et al. (2008) measured a significant excretion of 564 ethanol by $C$. auratus to the surrounding water within $2 \mathrm{~h}$ of initiation 565 of anoxia but found only a 50\% reduction in [PCr] after $10 \mathrm{~h}$ of anoxia 566 at $15{ }^{\circ} \mathrm{C}$. These results, considering the time needed for lactate produc- 567 tion, conversion to ethanol and diffusion into the water, and the ab- 568 sence of any initial rise in lactate concentration, suggest an immediate 569 activation of ethanol production.

570

When C. carassius is exposed to anoxia, lactate is shuttled to the mus- 571 cles for conversion to ethanol. The continuous rise in plasma [lactate] but 572 constant low muscle concentration indicates either that 1) the lactate 573 shuttling from blood to muscle is quite slow, or 2) that the lactate shuttle 574 is tightly regulated in a way that no more than the lactate that can be in- 575 stantly converted to ethanol is transported into the tissue. The first op- 576 tion seems most plausible since Mandic et al. (2008) measured 7 mol 577 lactate $\mathrm{g}^{-1}$ in white muscle of $C$. auratus after $10 \mathrm{~h}$ anoxia, indicating 578 higher transport of lactate into the tissue than can be quickly converted. 579 The presence of lactate accumulation in the study by Mandic et al. 580 (2008) but not in the present study is potentially a species-specific dif- 581 ference, but a slow shuttling mechanism combined with the relatively 582 short exposure period may have prevented detection of any lactate accu- 583 mulation in the muscle tissue in the present study.

\section{Conclusions}

Despite the significant difference in lactate accumulation, no differ- 586 ence in EPHOC: $\mathrm{O}_{2}$ deficit ratio could be detected between C. carassius 587 and $C$. carpio. As discussed above, the measured EPHOC for $C$. carassius 588 is in agreement with previous studies by being small compared to less 589 hypoxia tolerant and non-ethanol-producing species, but how C. carpio 590 achieves such a small EPHOC after near lethal anoxia exposure, without 591 depressing its metabolism or converting lactate into ethanol, is not eas- 592 ily explained. Despite its inability to produce ethanol in response to ox- 593 ygen deprivation, the metabolic profile of $C$. carpio is more similar to the 594 ethanol-producing members of Cyprinidae than other taxa that cannot 595 produce ethanol. C. carpio accumulates a greater EPHOC and requires 596 longer recovery time than $C$. carassius, but this is likely related to the 597 
severity of the anoxic exposure used in this study relative to the overall anoxia survival capability of each species. No lactate accumulation in white muscle of $C$. carassius and less severe accumulation in plasma, in comparison to $C$. carpio, probably indicates rapid implementation of the ethanol production pathway upon exposure to anoxia, but a slow shuttling mechanism from plasma to muscle. The results of the present study emphasize the importance of metabolic depression to $C$. carassius and $\mathrm{PCr}$ buffering capacity to $C$. carpio, and thus factors other than ability to produce ethanol are suggested to contribute in large part to EPHOC development in fishes.

\section{Acknowledgments}

J.C.S. was supported by a grant from the Danish Research Council to the research school SLIP and the Fishnet research network.

\section{References}

Behrens, J., Steffensen, J., 2007. The effect of hypoxia on behavioural and physiological aspects of lesser sandeel, Ammodytes tobianus (Linnaeus, 1785). Mar. Biol. 150, 1365-1377.

Bickler, P.E., Buck, L.T., 2007. Hypoxia tolerance in reptiles, amphibians, and fishes: life with variable oxygen availability. Annu. Rev. Physiol. 69, 145-170.

Brett, J.R., 1964. The respiratory metabolism and swimming performance of young sockeye salmon. J. Fish. Res. Board Can. 21, 1183-1226.

Bushnell, P.G., Steffensen, J.F., Schurmann, H., Jones, D.R., 1994. Exercise metabolism in two species of cod in arctic waters. Polar Biol. 14, 43-48.

Campbell, H.A., Fraser, K.P.P., Bishop, C.M., Peck, L.S., Egginton, S., 2008. Hibernation in an Antarctic fish: on ice for winter. PLoS One 3, e1743.

Dalla Via, J., Van den Thillart, G., Cattani, O., de Zwaan, A., 1994. Influence of long-term hypoxia exposure on the energy metabolism of Solea solea. 11. Intermediary metabolism in blood, liver and muscle. Mar. Ecol. Prog. Ser. 111, 17-27.

Dalla Via, J., van den Thillart, G., Cattani, O., Cortesi, P., 1997. Environmental versus functional hypoxia/anoxia in sole Solea solea: the lactate paradox revisited. Mar. Ecol. Prog. Ser. 154, 79-90.

Farrell, A.P., Richards, J.G., 2009. Defining hypoxia: an integrative synthesis of the responses of fish to hypoxia. Fish Physiol. 27, 487-503.

Hallman, T.M., Rojas-Vargas, A.C., Jones, D.R., Richards, J.G., 2008. Differential recovery from exercise and hypoxia exposure measured using 31P- and $1 \mathrm{H}-\mathrm{NMR}$ in white muscle of the common carp Cyprinus carpio. J. Exp. Biol. 211, 3237-3248.

Hochachka, P.W., 1986. Defense strategies against hypoxia and hypothermia. Science 231, 234-241

Hochachka, P.W., Mommsen, T.P., 1983. Protons and anaerobiosis. Science 219, 1391.

Holopainen, I.J., Hyvärinen, H., 1985. Ecology and physiology of crucian carp [Carassius carassius (L.)] in small Finnish ponds with anoxic conditions in winter. Verh. Int. Ver. Theor. Angew. Limnol. 22, 2566-2570.

Holopainen, I.J., Hyvärinen, H., Piironen, J., 1986. Anaerobic wintering of crucian carp (Carassius carassius L.) - II. Metabolic products. Comp. Biochem. Physiol. A: Physiol. 83, 239-242.

Hyvärinen, H., Holopainen, I.J., Piironen, J., 1985. Anaerobic wintering of crucian carp (Carassius carassius L.) I. Annual dynamics of glycogen reserves in nature. Comp. Biochem. Physiol. A: Physiol. 82, 797-803.

Johnston, I.A., Bernard, L.M., 1983. Utilization of the ethanol pathway in carp following exposure to anoxia. J. Exp. Biol. 104, 73-78.

ordan, A.D., Steffensen, J.F., 2007. Effects of ration size and hypoxia on specific dynamic action in the cod. Physiol. Biochem. Zool. 80, 178-185.

Killen, S.S., Costa, I., Brown, J.A., Gamperl, A.K., 2007. Little left in the tank: metabolic scaling in marine teleosts and its implications for aerobic scope. Proc. R. Soc. B 274, 431-438.

Lin, C., Wu, H., Tjeerdema, R., Viant, M., 2007. Evaluation of metabolite extraction strategies from tissue samples using NMR metabolomics. Metabolomics 3, 55-67.

Mandic, M., Lau, G.Y., Nijjar, M.M.S., Richards, J.G., 2008. Metabolic recovery in goldfish: a comparison of recovery from severe hypoxia exposure and exhaustive exercise. Comp. Biochem. Physiol. C 148, 332-338.

Maxime, V., Pichavant, K., Boeuf, G., Nonnotte, G., 2000. Effects of hypoxia on respiratory physiology of turbot, Scophthalmus maximus. Fish Physiol. Biochem. 22, 51-59.

Muusze, B., Marcon, J., van den Thillart, G., Almeida-Val, V., 1998. Hypoxia tolerance of Amazon fish: respirometry and energy metabolism of the cichlid Astronotus Ocellatus. Comp. Biochem. Physiol. A 120, 151-156.

Nilsson, G., 1988. A comparative study of aldehyde dehydrogenase and alcohol dehydrogenase activities in crucian carp and three other vertebrates: apparent adaptations to ethanol production. J. Comp. Physiol. B 158, 479-485

Nilsson, G.E., 1990. Long-term anoxia in crucian carp: changes in the levels of amino acid and monoamine neurotransmitters in the brain, catecholamines in chromaffin tissue, and liver glycogen. J. Exp. Biol. 150, 295-320.

Nilsson, G.E., 2001. Surviving anoxia with the brain turned on. News Physiol. Sci. 16, 217-221.

Nilsson, G.E., Renshaw, G.M.C., 2004. Hypoxic survival strategies in two fishes: extreme anoxia tolerance in the North European crucian carp and natural hypoxic preconditioning in a coral-reef shark. J. Exp. Biol. 207, 3131-3139.
Peake, S.J., Farrell, A.P., 2006. Fatigue is a behavioural response in respirometer- 673 confined smallmouth bass. J. Fish Biol. 68, 1742-1755.

Pichavant, K., Maxime, V., Thebault, M.T., Ollivier, H., Garnier, J.P., Bousquet, B., Diouris, 675 M., Boeuf, G., Nonnotte, G., 2002. Effects of hypoxia and subsequent recovery on tur- 676 bot Scophthalmus maximus: hormonal changes and anaerobic metabolism. Mar. Ecol. 677 Prog. Ser. 225, 275-285.

Piironen, J., Holopainen, I.J., 1986. A note on seasonality in anoxia tolerance of Crucian 679 carp (Carassius carassius (L)) in the laboratory. Ann. Zool. Fenn. 23, 335-338. 680

Richards, J.G., Heigenhauser, G.J.F., Wood, C.M., 2002. Glycogen phosphorylase and py- 681 ruvate dehydrogenase transformation in white muscle of trout during high- 682 intensity exercise. Am. J. Physiol. Reg. Int. Comp. Physiol. 282, R828-R836. 683

Scarabello, M., Heigenhauser, G.J.F., Wood, C.M., 1991. The oxygen debt hypothesis in 684 juvenile rainbow trout after exhaustive exercise. Respir. Physiol. 84, 245-259. 685

Schurmann, H., Steffensen, J.F., 1997. Effects of temperature, hypoxia and activity on 686 the metabolism of juvenile Atlantic cod. J. Fish Biol. 50, 1166-1180. 687

Shoubridge, E.A., Hochachka, P.W., 1980. Ethanol: Novel end product of vertebrate an- 688 aerobic metabolism. Science 209, 308-309.

Stecyk, J.A.W., Farrell, A.P., 2002. Cardiorespiratory responses of the common carp 690 (Cyprinus carpio) to severe hypoxia at three acclimation temperatures. J. Exp. 691 Biol. 205, 759-768.

Stecyk, J.A.W., Stenslökken, K.O., Farrell, A.P., Nilsson, G.E., 2004. Maintained cardiac 693 pumping in anoxic crucian carp. Science 306, 77.

Steffensen, J., 1989. Some errors in respirometry of aquatic breathers: how to avoid and 695 correct for them. Fish Physiol. Biochem. 6, 49-59. 696

Steffensen, J.F., Johansen, K., Bushnell, P.G., 1984. An automated swimming respirome- 697 ter. Comp. Biochem. Physiol. A: Physiol. 79, 437-440. 698

Svendsen, J.C., Tudorache, C., Jordan, A.D., Steffensen, J.F., Aarestrup, K., Domenici, P., 699 2010. Partition of aerobic and anaerobic swimming costs related to gait transitions 700 in a labriform swimmer. J. Exp. Biol. 213, 2177-2183.

Svendsen, J.C., Steffensen, J.F., Aarestrup, K., Frisk, M., Etzerodt, A., Jyde, M., 2012. Ex- 702 cess post hypoxic oxygen consumption in rainbow trout Oncorhynchus mykiss: re- 703 covery in normoxia and hypoxia. Can. J. Zool. 90, 1-11. 704

van den Thillart, G., van Waarde, A., 1993. The role of metabolic acidosis in the buffer- 705 ing of ATP by phosphagen stores in fish: an in vivo NMR study. In: Hochachka, P.W., 706 Lutz, P.L., Sick, T., Rosenthal, M., van den Thillart, G. (Eds.), Surviving Hypoxia: 707 Mechanisms of Control and Adaptation. CRC Press, pp. 237-252. 708

van den Thillart, G., Verbeek, R., 1991. Anoxia-induced oxygen debt of goldfish 709 (Carassius auratus L.). Physiol. Zool. 64, 525-540. 710

van den Thillart, G., van Berge-Henegouwen, M., Kesbeke, F., 1983. Anaerobic metabo- 711 lism of goldfish, Carassius auratus (L.): ethanol and $\mathrm{CO}_{2}$ excretion rates and anoxia 712 tolerance at 20, 10 and $5{ }^{\circ} \mathrm{C}$. Comp. Biochem. Physiol. A: Physiol. 76, 295-300. 713

van der Linden, A., Verhoye, M., Nilsson, G.E., 2001. Does anoxia induce cell swelling in carp 714 brains? In vivo MRI measurements in crucian carp and common carp. J. Neurophysiol. 715 $85,125-133$.

van Ginneken, V., van den Thillart, G., 2009. Metabolic depression in fish measured by 717 direct calorimetry: a review. Thermochim. Acta 483, 1-7. 718

van Ginneken, V., van den Thillart, G., Addink, A., Erkelens, C., 1995. Fish muscle energy 719 metabolism measured during hypoxia and recovery: an in vivo 31P-NMR study. 720 Am. J. Physiol. Reg. Int. Comp. Physiol. 268, R1178-R1187.

van Ginneken, V., Nieveen, M., Van Eersel, R, Van den Thillart, G., Addink, A, 1996, 722 Neurotransmitter levels and energy status in brain of fish species with and without 723 the survival strategy of metabolic depression. Comp. Biochem. Physiol. A 114, 724 189-196.

van Ginneken, V., Boot, R., Murk, T., van den Thillart, G., Balm, P., 2004a. Blood plasma 726 substrates and muscle lactic-acid response after exhaustive exercise in common 727 carp and trout: indications for a limited lactate-shuttle. Anim. Biol. 54, 119-130. 728

van Ginneken, V.J.T., Snelderwaard, P., van der Linden, A., van der Reijden, R., van den 729 Thillart, G., Kramer, K., 2004b. Coupling of heart rate with metabolic depression in 730 fish: a radiotelemetric and calorimetric study. Thermochim. Acta 414, 1-10. 731

van Raaij, M.T.M., Pit, D.S.S., Balm, P.H.M., Anton, B., van den Thillart, G., 1996. Behav- 732 ioral strategy and the physiological stress response in rainbow trout exposed to se- 733 vere hypoxia. Horm. Behav. 30, 85-92.

van Waarde, A., van den Thillart, G., Erkelens, C., Addink, A., Lugtenburg, J., 1990. Func- 735 tional coupling of glycolysis and phosphocreatine utilization in anoxic fish muscle. 736 An in vivo 31P NMR study. J. Biol. Chem. 265, 914-923.

Vianen, G.J., Thillart, G.E.E.J., Van Kampen, M., Van Heel, T.I., Steffens, A.B., 2001. Plasma 738 lactate and stress hormones in common carp (Cyprinus carpio) and rainbow trout 739 (Oncorhynchus mykiss) during stepwise decreasing oxygen levels. Neth. J. Zool. 740 51, 33-50.

Viant, M.R., Rosenblum, E.S., Tjeerdema, R.S., 2003. NMR-based metabolomics: a pow- 742 erful approach for characterizing the effects of environmental stressors on organ- 743 ism health. Environ. Sci. Technol. 37, 4982-4989. 744

Virani, N.A., Rees, B.B., 2000. Oxygen consumption, blood lactate and inter-individual 745 variation in the gulf killifish, Fundulus grandis, during hypoxia and recovery. 746 Comp. Biochem. Physiol. A 126, 397-405.

Wilkie, M.P., Pamenter, M.E., Alkabie, S., Carapic, D., Shin, D.S.H., Buck, L.T., 2008. Evidence 748 of anoxia-induced channel arrest in the brain of the goldfish (Carassius auratus). 749 Comp. Biochem. Physiol. C 148, 355-362.

Wissing, J., Zebe, E., 1988. The anaerobic metabolism of the bitterling Rhodeus amarus 751 (cyprinidaf, teleostei). Comp. Biochem. Physiol. B 89, 299-303.

Zhou, B.S., Wu, R.S.S., Randall, D.J., Lam, P.K.S., Ip, Y.K., Chew, S.F., 2000. Metabolic adjust- 753 ments in the common carp during prolonged hypoxia. J. Fish Biol. 57, 1160-1171. 754 